\title{
THE BATTLE OF EVIDENCE-BASED MEDICINE AND ANTI-VACCINATION MOVEMENTS
}

\author{
Y. Stoilova ${ }^{1}$, E. Hristova ${ }^{2}$, V. Rangelova ${ }^{1} *$ \\ ${ }^{1}$ Department of Epidemiology and Disaster Medicine, Faculty of Public Health, \\ Medical University of Plovdiv, Plovdiv, Bulgaria \\ ${ }^{2}$ Department of Social Medicine and Public Health, Faculty of Public Health, \\ Medical University of Plovdiv, Plovdiv, Bulgaria
}

\begin{abstract}
PURPOSE: "Vaccines are victims of their own success" as a result of the vigorous antivaccination movements and others like the anthroposophical study and homeopathy, which we define as temporary acting causes of ritually-religious and judicial character. Based on anti-vaccination sites on the internet we analyzed allegations and facts claimed by the supporter of those movements and questions asked by worried parents. Our aim was to refute those allegations and questions with evidence-based medical scientific answers. METHODS: For the purpose of the study official data from the Ministry of Health (MH), National centre for Infectious and Parasitic Diseases (NCIPD) and anti-vaccination sites was epidemiologically analyzed. RESULTS: Vaccination coverage of under 95\%(measles,mumps, rubella, diphtheria,tetanus, whooping cough) is a risk for an increase in the incidence and occurrence of epidemics(measles 2010 and 2017). The check-list of the anti-vaxxers includes: speculative and conspirative allegations with exciting content, articles in newspapers in which they claim to have classified information. CONCLUSION: New programs should be developed in order to increase the knowledge of parents about vaccines and to overcome the religious and regional barriers for prevention and control of infectious diseases. Cooperation between parents,physicians,pharmaceutical industry and the government is a key to success.
\end{abstract}

Key words: vaccines, infectious diseases, parents,children

\section{INTRODUCTION}

"Vaccines are victims of their own success" as a result of the vigorous anti-vaccination movements and others like the anthroposophical study and the homoeopathy which we define as temporary acting causes of ritually-religious and judicial character. Those movements are aimed at the vaccinepreventable diseases and they cause a serious harm to the surveillance and control of infectious diseases. The supporters of vaccines are striving to improve immunization policies while their opponents aim at discontinuation of vaccinations and they offer no alternative for

\footnotetext{
*Correspondence to: Vanya Rangelova, Department of Epidemiology and Disaster Medicine, Faculty of Public Health, Medical University of Plovdiv, Plovdiv, Bulgaria' Email:vaniaran1238@gmail.com'Phone: +35932/602855/+359883403683
}

the control of infectious diseases. One example of the import of a disease from countries where effective surveillance is lacking is the Netherlands. An outbreak of rubella that occurred first in the Netherlands among unvaccinated members of a religious community spread to Canada and USA in 2005. (1)

\section{MATERIALS AND METHODS}

Official data from the Ministry of Health, National centre for infectious and parasitic diseases and anti-vaccination sites have been used. For the aims of the study, epidemiological analysis was used.

\section{RESULTS}

Vaccination coverage of under 95\% (measles, diphtheria, tetanus, whooping cough, rubella, parotitis and others from the immunization calendar) is a risk of an increase in the 
STOILOVA Y, et al.

incidence, outbreaks and epidemics (measles 2010 and 2017, Bulgaria).According to the official information about the vaccination coverage for 2017 in our country, we can make and epidemiologic prognosis for the future epidemic processes (Table 1 and 2).

Table 1. Prognosis of the epidemic processes according to the completed mandatory immunizations for 2017

\begin{tabular}{cc}
\hline Mandatory vaccines & Immunization coverage (\%) \\
\hline $\begin{array}{c}\text { Tuberculosis } \\
\text {-newborns }\end{array}$ & 96.2 \\
\hline $\begin{array}{c}\text { Diphtheria,tetanus, whooping } \\
\text { cough,poliomyelitis, haemophilus influenzae type B } \\
-3^{\text {rd }} \text { dose completed }\end{array}$ & 92.3 \\
\hline $\begin{array}{c}\text { Hepatitis B } \\
-3^{\text {rd }} \text { dose completed }\end{array}$ & 91.9 \\
\hline $\begin{array}{c}\text { Measles,parotitis,rubella } \\
- \text { children above 13 months of age }\end{array}$ & 93.8 \\
\hline $\begin{array}{l}\text { Pneumoccal vaccine } \\
-3^{\text {rd }} \text { dose completed }\end{array}$ & 91.3 \\
\hline
\end{tabular}

Table 2. Vaccination coverage with mandatory vaccines (2010-2015)

\begin{tabular}{ccccccc}
\hline Vaccine & \multicolumn{5}{c}{ Vaccination coverage (\%) } \\
\cline { 2 - 7 } & $\mathbf{2 0 1 0}$ & $\mathbf{2 0 1 1}$ & $\mathbf{2 0 1 2}$ & $\mathbf{2 0 1 3}$ & $\mathbf{2 0 1 4}$ & $\mathbf{2 0 1 5}$ \\
\hline Tuberculosis & 97.8 & 97.7 & 97.0 & 97.2 & 96.7 & 95.8 \\
\hline $\begin{array}{c}\text { Hepatitis B (after 3 }{ }^{\text {rd }} \\
\text { dose) }\end{array}$ & 95.0 & 96.0 & 95.4 & 95.2 & 95.0 & 91.6 \\
\hline $\begin{array}{c}\text { Diphtheria,tetanus } \\
\text { Whooping cough (after } \\
3^{\text {rd }} \text { dose) }\end{array}$ & 94.1 & 95.1 & 95.3 & 94.9 & 87.5 & 90.7 \\
\hline $\begin{array}{c}\text { Poliomyelitis } \\
\text { (after 3 } 3^{\text {rd }} \text { dose) }\end{array}$ & 94.3 & 95.2 & 95.3 & 94.9 & 87.5 & 90.7 \\
\hline $\begin{array}{c}\text { Haemophilus influenza } \\
\text { type B } \\
\text { (after 3 } 3^{\text {rd }} \text { dose) }\end{array}$ & 91.1 & 95.1 & 95.3 & 94.9 & 82.7 & 90.5 \\
\hline $\begin{array}{c}\text { Streptococcus } \\
\text { pneumoniae } \\
\text { (3 }{ }^{\text {rd }} \text { dose) }\end{array}$ & 68.6 & 93.6 & 93.5 & 93.7 & 91.7 & 90.4 \\
\hline $\begin{array}{c}\text { Measles,mumps,rubella } \\
\text { (13 months of age) }\end{array}$ & 96.5 & 94.5 & 93.7 & 95.1 & 93.2 & 91.5 \\
\hline
\end{tabular}

Based on internet sites, we have worked out a check-list with manipulations, absurd questions, accusations and speculations for having exclusive classified information that the anti-vaxxers use to convince the society that the vaccines are dangerous and harmful.

We systematized the questions frequently asked by parents about the vaccines and present answers from the evidence-based medicine in the discussion.

\section{DISCUSSION}

The presented in Table $\mathbf{1}$ and $\mathbf{2}$ information reveals immunization coverage of under $95 \%$. The only exception is the tuberculosis vaccine. From 2010 to 2017 the vaccination indexes are marked by an alarming decline (2).
The danger of reemergence of not only sporadic cases but epidemics of vaccinepreventable diseases on our continent is real. The main reason are the vigorous antivaccination movements in Europe. More than 1 million children are not vaccinated against measles. Every year 32000 not vaccinated children die from this disease and 600000 newborns don't receive the vaccines for diphtheria, tetanus and whooping cough.

The beginning of the anti-vaccination movements was far in the past. In the years Edward Jenner introduced the smallpox vaccine part of the society renounced his invention with absurd allegations, caricatures and accusations. One positive thing is that Edward Jenner received honours and awards 
STOILOVA Y, et al.

for his breakthrough in the prevention of infectious diseases in the last years of his life.

The epidemiological importance of the actions of the anti-vaccination-movements in some countries in the last 30 years can be supported by the following facts: In the German democratic republic (GDR) in 1989 the vaccination coverage with pertussis vaccine was $95 \%$ and only 1-2 cases of the disease yearly were recorded, whereas in the former West German States (FWG) after the vaccine was being withdrawn the incidence was estimated at 160-180 cases/100.000 inhabitants in the 1970s-1980s (3).

In the USA in 1981 the anti-vaccination expert H. Coulter published the book "A shot in the dark" (4). The pediatric associations in the country and a lot of experts refuted the statements in the book. Unfortunately years after the publication of the book in 2012 in the USA the worst pertussis epidemic with 41,880 cases occured. Eighteen people died, including 15 infants younger than 1 (5). The Journal of the American Medical Association points out the fact that in the last 12 epidemics of pertussis $59-93 \%$ of the cases were in not vaccinated children (6).

In 2014 in Brooklyn, New York an epidemic of measles with 58 cases was registered among members of a religious community. According to $\mathrm{CDC}$, all the patients could be related to one index patient - intentionally unvaccinated adolescent aged 17 years who returned to New York City from London, United Kingdom, while infectious with measles (7). In the same year in Disneyland, California another outbreak of measles was registered and more than half of the affected patients were unvaccinated (8). In response to all the outbreaks, some of the states changed their legislation with respect to immunizations.

Between February 2017 and January $31^{\text {st }} 2018$ in Romania 5224 cases of measles were registered (9). At the same time in Serbia 3,812 cases of measles have been registered. The people affected are between 15 days old and 65 years of age. Ninety-five per cent of patients in Serbia were not vaccinated, partially vaccinated or with unknown vaccine status. (10)

Target groups to work with in connection with anti-vaccination movements in Bulgaria are:

- "hyper-informed Internet moms". To reassure them of the benefits of vaccination a Vaccine Benefit Website could be developed and a VaccineDamaged Children Fund might be established. Such funds are available in 19 countries, 11 of which are in Europe.

- The Roma population (through mediators)

- Internet sites and some media where nonprofessional discussions are taking place

- Immigrant communities

- General physicians and their patients in a direction of improving the trust between them

On the Internet, parents can find many absurd allegations, to which the evidence-based medicine gives answers:

1. Not vaccinated children are healthier and more vital - False:

The higher morbidity in nurseries and kindergartens according to these "experts" is probably due to the fact that children visiting those institutions are vaccinated.

The truth is that the reason for the higher morbidity is flaws in the epidemiological regime and control. Mainly the children are suffering from scarlet fever and varicella. For scarlet fever, there is no vaccine and the vaccine for varicella in our country is still not mandatory.

2. Vaccinated children have delays in their neurological development- False

3.The laws for mandatory vaccinations violate personal rights of people- False

The beginning was in 1905. with the appeal of pastor Jacobson, fined $\$ 5$, for refusing to vaccinate during the smallpox outbreak, as he denied the necessity of vaccinations. The US Supreme Court has made one of the most important decisions in the field of public health, which has been applied consistently to our day (Jacobson v. Massachusetts): "Freedom conferred by the Constitution does not give absolute freedom to everyone to be completely free from restrictions. Society cannot function without the safety of its members (11) According to the Supreme Court, the state was created to protect and secure the safety, prosperity and happiness of all, not for the benefit of a particular person.

Prophylaxis with vaccines as well as treatment should be performed after informed consent.

The Court does not declare coercion as an absolute principle protecting the public good but introduces five conditions that must exist to assume that the violation of personal liberty is justified and complies with the Constitution: The first is the existence of a health necessity (counter- Polio is still not eradicated, but cases are still reported in three countries (Afghanistan and Pakistan and Nigeria), its severity and the presence of objective data on 
the risk of infection, but also a sufficient argument in favour of the need for immunization against the infectious disease. The same applies to diseases such as measles, rubella, pertussis, which can lead to serious complications, disability and death.

The second is the reason for the action taken: it is not justified to ban access to countries where polio is still present, nor does it makes sense for their citizens to be restricted in their movement in order to prevent others from spreading this disease. However, it is fully justified to require immunization of the population against poliomyelitis, provided that a program for its eradication is implemented globally.

Third and Fourth -Proportionality and fairness - the measures should correspond to the danger and not be arbitrary.

Fifth avoidance of harm - risk to health outweighing the benefits (when there is a proven medical contraindication for vaccination).In response to the concerns of parents that thiomersal causes autism, no vaccines with thiomersal are used in the United States and Europe, although no causal relationship has been established between the two.

The following questions that worry some of
the parents need professional answers:
- Why my unvaccinated child could
be a threat for the other vaccinated
children?
Answer: Collective immunity relies on Answer: Collective immunity relies on
collective effort - Remember Hardin's story for the pasture - to imagine that it is the collective immunity of a territory (school, kindergarten, district, state) (12). While everyone respects the size of the pastureland and other farmers, the pasture will be maintained in good shape to feed each animal. If everyone begins to think about their individual welfare and to place other animals on the pasture, i.e. not to vaccinate their children or themselves, the collective immunity will soon be unable to fulfil its purpose and conditions for an increase in the incidence and occurrence of epidemics of vaccine-preventable diseases will be available. The epidemiological answer to this question of the parents is: In every population, there are people who cannot be vaccinated due to the presence of medical contraindications (autoimmune diseases, allergies, cytostatic treatments, etc.). In addition to this, no vaccine gives $100 \%$ post-vaccination immunity. Nonimmunized people are protected if a certain
STOILOVA Y, et al. level of collective immunity is being maintained. The decline in the vaccination coverage as a result of voluntary actions of the parents because of hypothetical adverse reactions leads to that limit, after which the epidemic is inevitable and Hardin's tragedy occurs. Collective immunity requires about $95 \%$ of the population in the population to be vaccinated.

- With no polio in Europe since 2001, why do we need to immunize children against this disease?

Answer: There is no polio in Europe, but in 2001 there were two cases in Bulgaria imported from India through the port of Burgas (13). In Syria, for 2 years of civil war, 32 cases of polio were reported. For the purpose of eradication of poliomyelitis World Health Organization (WHO) used 16 million doses of live polio vaccine for all children in the Middle East, Turkey, including Egypt.

- The vaccine against measles causes autism.

Answer: This statement was first made by the British gastroenterologist Andrew Wakefield. He claimed that there was a causal relationship between the administration of the measles vaccine and the appearance of symptoms from the autistic spectrum in the patients he had studied. After a thorough investigation, the claims were rejected and Wakefield's medical rights were suspended because of distribution of misleading information. (14). The truth is: the time of the first occurrence of autism symptoms and early childhood vaccination are largely at the same time. There are excellent studies available now on children with Autism that proves the disease is genetic. Another ingredient of the measles vaccine claimed to increase the risk of autism was thiomersal. Despite the fact nowadays there is no thiomersal in the vaccine the registered cases of autism are on the rise. (15)

\section{- Vaccines can kill a child}

Answer: Vaccines do not kill children. After administration of the vaccine several local and systemic reactions could be observed-rash, redness and elevated temperature. In 5 to $10 \%$ of the vaccinated against measles fever and rash lasting eight to ten days may occur. Also in 1 in every 24,000 children, this vaccine may cause a reduction in the blood cells, which does not lead to death or prolonged hospitalization.

- Children get sick after vaccinations. Answer: When Albert Sabin created the oral polio vaccine he conducted the second stage of the testing of the vaccine he has created on his two daughters. Currently, vaccines do not contain microorganisms (wild), but processed 
or artificially created particles of the causative agents that cannot cause disease. Vaccines are one of the most strictly controlled bio-products because they are administered to healthy children and even the smallest adverse reaction will not be forgiven by parents and the society. In our country, according to official data for 2017 over 2 million people have been vaccinated and 60 adverse effects have been reported.

- Vaccines are dangerous because:

- There is aluminium in them!

Answer: Aluminium is the third most common metal in the environment - it could be found in drinking water, in many foods. In some vaccines, aluminium is added in order to stimulate a quicker response of the immune system. If a child receives all the mandatory vaccines, he will receive for 6 months $4 \mathrm{mg}$. aluminum, while on the other hand in breast milk there is over $10 \mathrm{mg}$. aluminium and over 100 in baby formulas (16).

-There is mercury in them

Answer: In the 90's mercury was removed as a preservative at the insistence of mothers. Hepatitis B vaccine has no thiomersal since 2008. After removing thiomersal, the same mothers protested further that the vaccine was still harmful after the ingredient was removed. It is methylmercury rather than ethylmercury (thiomersal) that could cause harm. 400,000 million dollars were needed for new research to prove the already known - Mercury in the form of thiomersal is not harmful to health. But it was still removed! (17)

- There is formaldehyde in them

Answer: Formaldehyde "kills" (attenuate) viruses or bacteria. After purification from formaldehyde, only traces are found, much less than those found in the blood (18)

- There's gelatin in them

Answer: Gelatin is a stabilizer which has been hydrolyzed and "purified" and the consequences from it are described as "redness for about an hour" at the injection site, much less than the allergic skin reaction upon contact with pollen. (19)

\section{- The vaccines overload the immune system}

Answer: Misunderstood ideas for a healthy lifestyle with less chemistry and medications for people lead to: in Bulgaria: newborn children grow without protection and put others at risk. There is growing agreement between parents and general practitioners for entries of uncompleted immunizations which was one of the reasons for an epidemic of measles with about 24,000 people in 2009/2010. and 24 death cases against 0 cases of measles between 2002-2009.
Medical science has provided vaccines against over 20 serious illnesses and evidence of success should serve as a lesson. Theoretically, the child's immune system can respond to 10,000 vaccines. The use of 11 vaccines uses only $0.1 \%$ of the child's immune system. Modern vaccines are maximally purified from non-immunogenic antigens, for example in 1 vaccine (against variola) - 200 antigens existed, and today in 11 vaccines there are 130 antigens.

\section{- Some institutions benefit economically from vaccines.}

Answer: Pharmaceutical companies would be more financially profitable if they do not produce vaccines, but medications for the diseases that are prevented by vaccines. As for healthcare institutions, for example, the more children are vaccinated for pneumococci, the fewer complications and hospital treatment will be needed and more money will be saved.

\section{CONCLUSION}

The relevant scientific facts are not sufficient enough to cope with the anti-vaccination movements. Initiatives are needed to develop programs based on the social impact of infectious diseases to overcome the lack of knowledge of parents, social, religious and regional barriers for prevention and control of infectious diseases. The cooperation between parents, physicians, economists, the pharmaceutical industry and the governments is a key to success.

\section{REFERENCES}

1. Hahné S, Macey J, Tipples G, Varughese Paul, King A, van Binnendijk R, Ruijs Helma, van Steenbergen J, Timen A, van Loon A. M., de Melker H. Rubella outbreak in an unvaccinated religious community in the Netherlands spreads to Canada. Euro Surveill. 2005;10(20)

2. Кунчев А. "Имунизационна политика на Р. България." Българско сдружение по иновативна медицина "Ваксините действат за да ни защитят" 20-21 април 2018 г. Велинград;

3. Hellenbrand W., Beier D., Jensen E., Littmann M., Meyer C., Oppermann H., König C.H.W. and Reiter S. The epidemiology of pertussis in Germany: past and present ; BMC Infectious Diseases 2009 9:22;

4. H Coulter, Fisher L. B., A Shot in the Dark ; Avery Publishing Group Inc.,U.S. 31 Oct 1991

5. https://www.cbsnews.com/news/2012worst-whooping-cough-year-for-us-since1955/ 
6. Austrew A., New Study Proves What We Already Knew: Anti-Vaxxers Make Everyone Sick; http://www.scarymommy.com/studyproves-anti-vaxxers-contribute-to-measlespertussis/

7. Notes from the Field: Measles Outbreak Among Members of a Religious Community - Brooklyn, New York, March-June 2013; CDC, MMWR September 13, 2013 / 62(36);752-753

8. Zipprich J, Winter K, Hacker J, Xia D, Watt J, Harriman K. Measles Outbreak California, December 2014-February 2015. MMWR Morbidity and Mortality Weekly Report. 2015;64(6):153-154.

9. Measles outbreaks still ongoing in 2018 and fatalities reported from four countries; European Centre for Disease Prevention and Control ; 9 Mar 2018 https://ecdc.europa.eu/en/newsevents/measles-outbreaks-still-ongoing2018-and-fatalities-reported-four-countries

10.http://outbreaknewstoday.com/serbiareports-significant-increase-measles-80667/

11. Willrich M. Pox: An American History (Penguin History of American Life) Penguin Books; Reprint edition (March 27, 2012)

12.Hardin, G (1968). "The Tragedy of the Commons". Science. 162 (3859): 12431248. doi:10.1126/science.162.3859.1243. PMID 5699198.
STOILOVA $Y$, et al.

13.https://www.dnevnik.bg/intervju/2013/11/1 3/2180934_dr_angel_kunchev_glaven_zdra ven_inspektor_ima_risk_ot/

14. Wakefield AJ1, Murch SH, Anthony A, Linnell J, Casson DM, Malik M, Berelowitz M, Dhillon AP, Thomson MA, Harvey P, Valentine A, Davies SE, Walker-Smith JA. Ileal-lymphoid-nodular hyperplasia, nonspecific colitis, and pervasive developmental disorder in children. ; The Lancet. 1998 Feb 28;351(9103):637-41.

15.Farrington P. C.,Miller E., Taylor B. MMR and autism: further evidence against a causal association ; Vaccine ; Volume 19, Issue 27, 14 June 2001, Pages 3632-3635

16. Mandell GL, Bennett JE, Dolin R, eds., Principles and Practices of Infectious Diseases, Philadelphia, PA: Churchill Livingstone, 2000

17.Ball K. L, Ball R and Pratt D. R. An Assessment of Thimerosal Use in Childhood Vaccines Pediatrics $2001 ; 107 ; 1147-1154$

18. Ong C. K, Devi S, Cardosa J. M. and Wong T. K. Formaldehyde-Inactivated Whole-Virus Vaccine Protects a Murine Model of Enterovirus 71 Encephalomyelitis against Disease J. Virol. January 2010 vol. 84 no. 1 661-665

19.Plotkin SA, Orenstein WA, and Offit PA, eds., General Immunization Practices;Vaccines Fifth Edition, Saunders Elsevier, 2008 